\title{
TRANSPORT OF COPPER(II) THROUGH SUPPORTED LIQUID MEMBRANE CONTAINING LIX65N
}

\author{
Toshihiko IMATO, Hosei OGAWA, Shigeharu MOROOKA \\ AND YASUO KATO \\ Department of Applied Chemistry, Faculty of Engineering, \\ Kyushu University, Fukuoka 812
}

\begin{abstract}
Permeation rate and transfer mechanism of copper(II) through a supported liquid membrane containing LIX65N as a mobile carrier were studied. The experiment was carried out under the condition that the rate-determining step of the dialysis was the diffusion in the membrane.

The binary diffusivities of the oxime and the copper-oxime complex for solute-solvent system and apparent diffusivity of copper in the supported liquid membrane were measured. The apparent diffusivity of copper was approximately proportional to the $-\mathbf{1 . 0}$ power of the liquid membrane solution viscosity. The copper flux was constant in the range of $\mathrm{pH}>3$ in the feed solution, but decreased with decreasing $\mathrm{pH}$ in the range of $\mathrm{pH}<3$. Copper concentration in the feed solution hardly influenced the copper flux in the range of $10^{-8}-10^{-1} \mathrm{~mol} \cdot \mathrm{dm}^{-3}$. The copper flux was proportional to the 1st power of the oxime concentration in the liquid membrane when pH of the feed solution was 4.47 , but the value of the power of the oxime concentration increased with decreasing value of $\mathrm{pH}$ of the feed solution. The concentration profile of the copper-oxime complex in a stack of the supported liquid membrane was approximately in agreement with the theory.
\end{abstract}

\section{Introduction}

Use of liquid membrane containing liquid ion exchanger, chelating agent or crown polyether as a mobile carrier is one of the most promising separation techniques ${ }^{3,4,6,8,10,13,14,16,17)}$. Two configurations of liquid membrane have been reported. One is $\mathrm{W} / \mathrm{O} / \mathrm{W}$ type emulsion membrane $e^{8,16,17)}$, and the other is supported liquid membrane $e^{3,4,6,10,13,14)}$. From the engineering standpoint, the latter could be more practical for recovering concentrated solutes, because of its stability and simplicity ${ }^{13}$. However, systematic studies on permeation rates and diffusivities of carrier and carrier complex in the supported liquid membrane are not sufficient to date.

In the present investigation, the chelating reagent LIX $65 \mathrm{~N}$ is used as a mobile carrier. The extraction equilibrium of copper between aqueous and membrane phases is measured, and the diffusivities of the oxime and the copper complex in the supported liquid membrane are determined. The effects of $\mathrm{pH}$ and cupric ion concentration in the feed solution and carrier concentration in the supported liquid membrane on the permeation rate of cupric ion are also examined.

\section{Experimental}

Received June 6, 1980. Correspondence concerning this article should be addressed to Y. Kato.

\section{1 Chelating reagent and solvents}

LIX65N (General Mills Inc. lot no. 4B19126) was diluted with kerosene, phthalic acid diesters (dibutylphthalate (DBP), dioctylphthalate (DOP), dinonylphthalate (DNP)) or their mixtures, and was used as a mobile carrier. The active oxime concentration in LIX $65 \mathrm{~N}$ was determined by the "ultimate loading" method described by Whewell et al. ${ }^{199}$.

\section{2 Extraction equilibria}

Distribution ratio of copper, $E$, is defined by the ratio of total copper concentration in organic phase to that in aqueous phase. To obtain $E$, an aqueous solution containing $1.0 \times 10^{-3} \mathrm{~mol} \cdot \mathrm{dm}^{-3}$ cupric sulfate and an organic solution of the same volume containing a large excess of the oxime were mixed and equilibrated by shaking at $303 \mathrm{~K}$. The cupric ion concentration in the aqueous solution was analysed with a Jarrel Ash AA-1 atomic absorption spectrophotometer. The amount of copper complex in the organic solution was calculated from the mass balance of copper. Ionic strength in the aqueous solution was adjusted to $0.2 \mathrm{~mol} \cdot \mathrm{dm}^{-3}$ with sodium perchlorate, and $\mathrm{pH}$ was adjusted to a fixed value with acetic acid and sodium acetate.

\section{3 Diffusion cell and preparation of membrane}

The diffusion cell is illustrated in Fig. 1. The lower and upper compartments with inner diameter of $0.06 \mathrm{~m}$ were made of acrylic resin and were stirred individually by Teflon-coated magnetic stirrers $0.04 \mathrm{~m}$ 


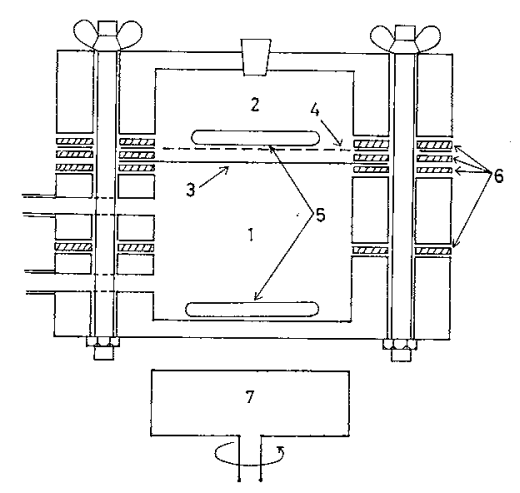

1: lower cell containing feed solution

2: upper cell containing stripping solution

3: supported liquid membrane

4: nylon net 5: stirrer

6: silicon rubber sheet 7: magnet

Fig. 1 Diffusion cell

long. The stirring rate was about $3 \mathrm{~Hz}$. The cell was placed in a water bath at $303 \mathrm{~K}$.

The liquid membrane solution was prepared by dissolving a certain amount of LIX65N in each solvent. The support was a porous polymer membrane of polypropylene, Duragard 2500 (Polyplastics Co., Ltd.), which was identical to Celgard 2500 (Celanese Plastics Co.). According to the manufacturer's specification, the average pore size was $0.04 \mu \mathrm{m} \times 0.4 \mu \mathrm{m}$. The pores of the porous polymer support were filled with the liquid membrane solution under vacuum as described by Lee et al. ${ }^{14}$. When the porous polymer support was impregnated with the organic solution, it was a little swollen. The fraction of solvent per unit volume of the supported liquid membrane was found to be $0.57-0.59$ by measurement of weight difference between the dry membrane stack and the solvent-impregnated one, and the average thickness of the latter was $2.68 \times 10^{-5} \mathrm{~m}$ per each sheet.

\section{4 Diffusion dialysis}

The lower cell was filled with $1.2 \times 10^{-1} \mathrm{dm}^{3}$ of an aqueous solution of cupric sulfate (feed solution). The $\mathrm{pH}$ value of the solution was adjusted by adding acetate buffer solution. To reduce the concentration polarization outside the membrane, the concentration of copper in the feed solution was held greater than that of oxime in the membrane except for the case of examination of the effect of copper concentration on copper flux. The upper cell was filled with $6.0 \times$ $10^{-2} \mathrm{dm}^{3}$ of hydrochloric acid solution (stripping solution). The cupric ion concentration in the upper cell was determined periodically with the atomic absorption spectrophotometer by taking samples of $2.0 \times 10^{-3} \mathrm{dm}^{3}$ with pipette. The volume of the solution in the upper cell was kept constant by replacing the sampled liquid with fresh stripping solution, and the change in concentration by this sampling procedure was numerically corrected. The copper flux was calculated from the slope of the time-dependent concentration curve for the upper cell.

The concentration profile of copper-oxime complex in the membrane phase was determined by using stacked membranes (8-10 sheets). After a steady state of diffusion dialysis was attained, the stack was quickly disassembled. Each membrane was immersed in aqueous $\mathrm{HCl}$ solution of $1 \mathrm{~mol} \cdot \mathrm{dm}^{-3}$ for $24 \mathrm{~h}$ and the concentration of copper extracted into the aqueous solution was determined by the atomic absorption spectrophotometer. The concentration of copper complex in each membrane was calculated from the amount of eluted cupric ion and the volume of the membrane impregnated with the solvent.

\subsection{Measurement of diffusivity in supported liquid membrane}

To determine the binary diffusivities of the oxime and the copper-oxime complex for solute-solvent system in the supported liquid membrane, the following unsteady-state dialysis was carried out. A stack of the membranes ( $8-10$ sheets) impregnated with pure DOP was clamped between the two half cells. The lower cell was filled with the oxime or the copperoxime complex, dissolved in DOP, and the upper cell was filled with pure DOP. The time-dependent concentration of the oxime in the upper cell was periodically measured by Simadzu UV-180 Spectrometer at a wave length of $317 \mathrm{~nm}$. Copper in the upper cell was extracted with an aqueous $\mathrm{HCl}$ solution and determined with the atomic absorption spectrophotometer.

The diffusion of the solute (oxime or copper-oxime complex) through the membrane impregnated with pure DOP in the region of $0 \leqq x \leqq d$ is governed by the following equation:

$$
\partial C / \partial t=D_{s}\left(\partial^{2} C / \partial x^{2}\right)
$$

where $D_{s}$ and $C$ represent the binary diffusivity for the solute-solvent system in the liquid membrane and the concentration of the solute, respectively.

The initial and boundary conditions are

$$
\begin{array}{llllll}
t=0 & x \leqq 0 & C=C_{0} & \text { and } & x>0 & C=0 \\
t>0 & x=0 & C=C_{0} & \text { and } & x=d & C=0
\end{array}
$$

where the solute concentration in the upper cell is sufficiently lower than that in the lower cell.

The solution of Eq. (1) consistent with the above initial and boundary conditions is given by $\mathrm{Crank}^{5)}$. The total amount of diffusing solute, $Q_{t}$, approaches the line as $t \rightarrow \infty$

$$
Q_{t}=\left(D_{s} C_{0} / d\right)\left\{t-\left(d^{2} / 6 D_{s}\right)\right\}
$$

Therefore, the time lag, $\Delta t$, and the flux of solute under steady state, $J_{s}$, are obtained.

$$
\Delta t=d^{2} / 6 D_{s}
$$




$$
J_{s}=D_{s} C_{0} / d
$$

\section{Theory}

Theories of carrier-facilitated transport and coupled transport in the liquid membrane have been proposed by several authors ${ }^{3,4,6,17,18)}$. The present theory is based on the following assumptions, which are fundamentally the same as those of Baker et al. ${ }^{31}$ and Völkel et al. ${ }^{17}$.

1) Local distribution of cupric ion at the membrane interface is in equilibrium.

2) Formation and dissociation of copper complex take place rapidly so that diffusion through the membrane is the rate-determining step.

Figure 2 shows the schematic concentration profile of diffusing species, where $\mathrm{H}_{2} \mathrm{~L}$ and $\mathrm{Cu}(\mathrm{HL})_{2}$ represent the oxime and its copper complex, respectively. The extraction reaction occurring at $x=0$ and $x=d$ is expressed as follows ${ }^{1,2,11,12)}$ :

$$
\mathrm{Cu}^{2+}(\mathrm{aq})+2 \mathrm{H}_{2} \mathrm{~L}(\text { org }) \leftrightarrows \mathrm{Cu}(\mathrm{HL})_{2}(\text { org })+2 \mathrm{H}^{+}(\mathrm{aq})
$$

The extraction constant of the reaction, $K_{\mathrm{ex}}$, is given by

$$
K_{\theta \mathrm{X}}=C_{\mathrm{Cu}(\mathrm{HL})_{2}}(\mathrm{org}) C_{\mathrm{H}}{ }^{2}(\mathrm{aq}) / C_{\mathrm{H}_{2} \mathrm{~L}}{ }^{2}(\mathrm{org}) C_{\mathrm{Cu}_{\mathrm{u}}}(\mathrm{aq})
$$

By arranging Eq. (8), the distribution ratio of copper, $E$, is derived as follows.

$$
\log E=\log K_{\text {ex }}+2 \log C_{\mathrm{H}_{2} \mathrm{~L}} \text { (org) }+2 \mathrm{pH}
$$

Under the steady-state condition, the fluxes of $\mathrm{H}_{2} \mathrm{~L}$ and $\mathrm{Cu}(\mathrm{HL})_{2}$ across the membrane are given by the following equations.

$$
\begin{aligned}
J_{\mathrm{H}_{2} \mathrm{~L}}=( & \left(D_{\mathrm{M}, \mathrm{H}_{2} \mathrm{~L}} / d\right) \cdot\left\{\left.C_{\mathrm{H}_{2} \mathrm{~L}}(\mathrm{M})\right|_{d}-\left.C_{\mathrm{H}_{2} \mathrm{~L}}(\mathrm{M})\right|_{0}\right\} \\
J_{\mathrm{Cu}(\mathrm{HL})_{2}}= & \left(D_{\mathrm{M}, \mathrm{Cu}(\mathrm{HL})_{2}} / d\right) \cdot\left\{\left.C_{\mathrm{Cu}(\mathrm{HK})_{2}}(\mathrm{M})\right|_{0}\right. \\
& \left.-\left.C_{\mathrm{Cu}(\mathrm{HL})_{2}}(\mathrm{M})\right|_{d}\right\}
\end{aligned}
$$

The concentration of species $i$ per unit volume of membrane, $C_{i}(\mathrm{M})$, is related to the concentration in the organic phase, $C_{i}(\mathrm{org})$, as follows.

$$
C_{i}(\mathrm{M})=C_{i}(\text { org }) \cdot \varepsilon
$$

where $\varepsilon$ is the porosity of the membrane.

The extraction constant based on the unit volume of membrane is given by

$$
K=K_{\text {ex }} / \varepsilon
$$

From the chemical stoichiometry, one gets

$$
J_{\mathrm{H}_{2} \mathrm{~L}}=2 J_{\mathrm{Cu}(\mathrm{HL})_{2}}
$$

Solubility of $\mathrm{H}_{2} \mathrm{~L}$ in the aqueous phase is so small that the mean total concentration of oxime in the membrane is given by

$$
\hat{C}_{\mathrm{H}_{2} \mathrm{~L}} \mathrm{~L}(\mathrm{M})=(1 / d) \cdot \int_{0}^{d}\left\{2 C_{\mathrm{Cu}(\mathrm{HL})_{2}}(\mathrm{M})+C_{\mathrm{H}_{2} \mathrm{~L}}(\mathrm{M})\right\} d x
$$

From Eqs. (8) and (10)-(15), the concentration of $\mathrm{Cu}(\mathrm{HL})_{2}$ at $x=0$ is expressed by the following equa-

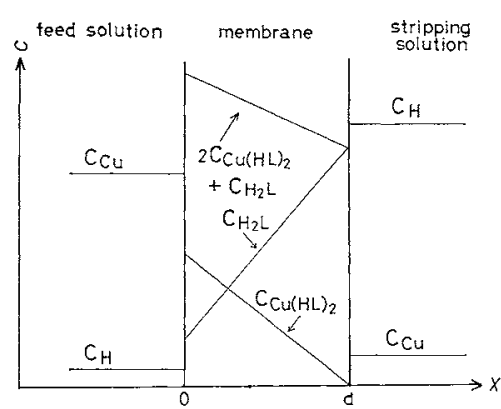

Fig. 2 Schematic concentration profile

tion by assuming that the concentration of $\mathrm{Cu}(\mathrm{HL})_{2}$ at $x=d$ is zero.

$$
\begin{gathered}
\left.C_{\mathrm{Cu}(\mathrm{HL})_{2}}(\mathrm{M})\right|_{0}=\left\{C_{\mathrm{H}}{ }^{2}(\mathrm{~F})+2(\alpha+1) K C_{\mathrm{Cu}}(\mathrm{F}) \hat{C}_{\mathrm{H}_{2} \mathrm{I}}(\mathrm{M})\right. \\
\left.-\sqrt{C_{\mathrm{H}}{ }^{4}(\mathrm{~F})+4(\alpha+1) K C_{\mathrm{Cu}}(\mathrm{F}) C_{\mathrm{H}}{ }^{2}(\mathrm{~F}) \hat{C}_{\mathrm{H}_{2} \mathrm{I}}(\mathrm{M})}\right\} \\
/\left\{2 K(\alpha+1)^{2} C_{\mathrm{Cu}}(\mathrm{F})\right\}
\end{gathered}
$$

where $\alpha=D_{\mathrm{M}, \mathrm{Cu}(\mathrm{HL})_{2}} / D_{\mathrm{M}, \mathrm{H}_{2} \mathrm{~L}}$.

From Eqs. (11) and (16), the flux of copper is obtained.

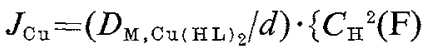

$$
\begin{aligned}
& +2(\alpha+1) K C_{\mathrm{Cu}}(\mathrm{F}) \hat{C}_{\mathrm{H}_{2} \mathrm{~L}}(\mathrm{M}) \\
& \left.-\sqrt{C_{\mathrm{H}}{ }^{4}(\mathrm{~F})+4(\alpha+1) K C_{\mathrm{Cu}}(\mathrm{F}) C_{\mathrm{H}}{ }^{2}(\overline{\mathrm{F}}) \hat{C}_{\mathrm{H}_{2} \mathrm{~L}}(\mathrm{M})}\right\} \\
& /\left\{2 K(\alpha+1)^{2} C_{\mathrm{Cu}}(\mathrm{F})\right\}
\end{aligned}
$$

In the case of $\alpha=1$, this equation becomes identical to that reported by Völkel et al. ${ }^{17)}$.

\section{Results and Discussion}

\section{1 Extraction equilibria}

Figure 3 shows the distribution ratio of copper for the oxime dissolved in the phthalic acid diesters. With these data, the extraction constant is calculated from Eq. (9). As shown in Table 1, the value of $K_{\text {ex }}$ increases with the alkyl chain length of the diluent molecule.

\section{2 Diffusivities in supported liquid membrane}

Figure 4 shows the time-dependent concentrations of the oxime and the copper-oxime complex in the upper cell. The dialysis system was described in Section 1.5. By using the time lag, the binary diffusivity for the solute-solvent system in the supported liquid membrane was calculated from Eq. (5). When DOP was used as the membrane solution, the binary diffusivities of the oxime and the copper-oxime complex at $303 \mathrm{~K}$ were $3.0 \times 10^{-12}$ and $2.0 \times 10^{-12} \mathrm{~m}^{2} \cdot \mathrm{s}^{-1}$, respectively. On the other hand, the binary diffusivities of the oxime and the copper-oxime complex calculated from the steady-state fluxes by using Eq. (6) were $3.7 \times 10^{-12}$ and $2.4 \times 10^{-12} \mathrm{~m}^{2} \cdot \mathrm{s}^{-1}$, respectively. The agreement between the diffusivities cal- 


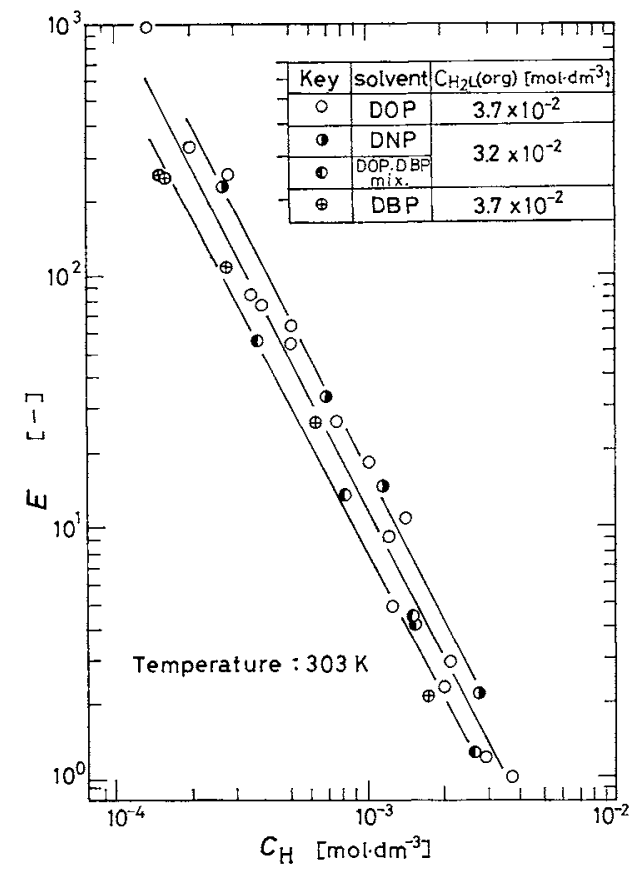

Fig. 3 Extraction equilibria of copper with LIX65N in various phthalic acid diesters

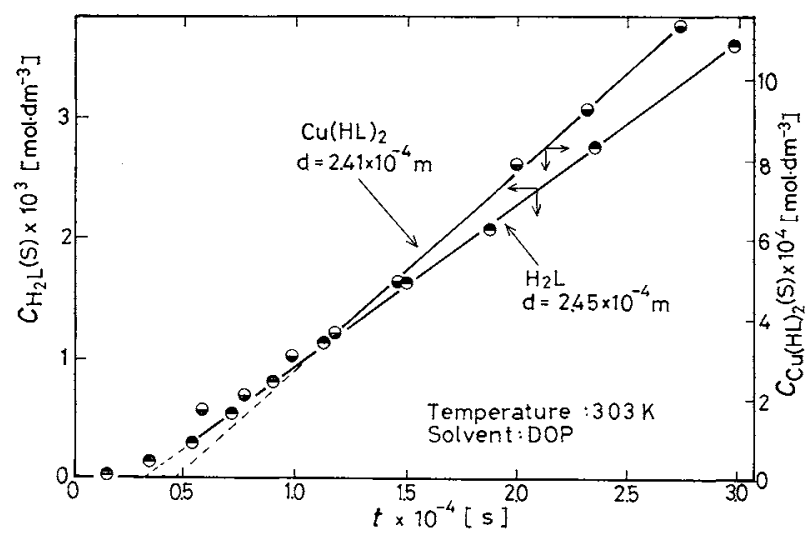

Fig. 4 Time-dependent concentration of oxime and copper-oxime complex in upper cell

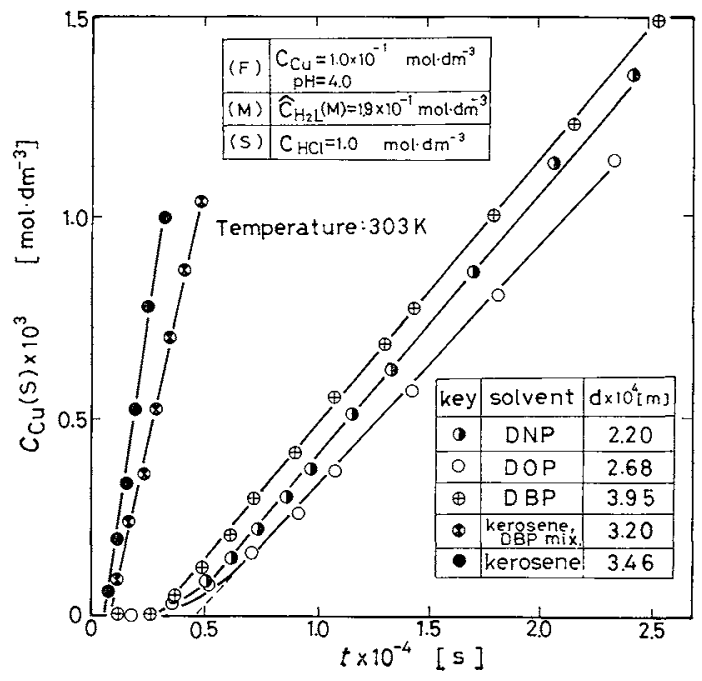

Fig. 5 Time-dependent concentration of copper in upper cell
Table 1 Extraction constants for various phthalic acid diesters at 303K

\begin{tabular}{cc} 
Solvent & $K_{\text {ex }}[-]$ \\
\hline DBP & $7.9 \times 10^{-3}$ \\
DOP, DBP mixture & $7.9 \times 10^{-3}$ \\
DOP & $1.0 \times 10^{-2}$ \\
DNP & $2.0 \times 10^{-2}$ \\
\hline
\end{tabular}

culated from the time lag and from the steady state flux is within $20 \%$.

The time-dependent concentrations of copper in the stripping solution are illustrated in Fig. 5. The dialysis system was described in Section 1.4 and stacked membranes were used. The time lag was observed for this coupled transport system similarly to the solute-solvent binary diffusion system. Since there was no remarkable difference between the diffusivities of the oxime and the copper-oxime complex for the binary diffusion system, we can approximately apply Eq. (5) to the coupled transport system. The apparent diffusivity of copper in the membrane impregnated with DOP solution of oxime was intermediate between values of the binary diffusivities of oxime and copper-oxime complex.

In the case of kerosene as membrane solution, the time lag can be measured as accurately as for phthalic acid diesters. In Figure 6, the apparent diffusivities calculated from the time lag shown in Fig. 5 are plotted as a function of the viscosity of the membrane solution. The apparent diffusivity is found to be proportional to -1.0 power of the viscostiy of the membrane solution up to about $3 \times 10^{-3} \mathrm{~Pa} \cdot \mathrm{s}$ of low-viscosity membrane solution such as kerosene. In addition, though a figure is not shown, the copper flux as well as the apparent diffusivity is proportional to -1.0 power of the viscosity of the membrane solution. These results indicate that the diffusion of copper-oxime complex across the liquid membrane is the ratedetermining step even when kerosene is the membrane solution.

The diffusivity in a membrane with micro-pores is related to that in the bulk organic solvent by the following equation ${ }^{7}$ :

$$
D_{M}=\varepsilon D_{B} / \tau^{2}
$$

where $\tau$ is the tortuosity of the membrane. Mackie and Meares ${ }^{15}$ have expressed the tortuosity as a function of the volume fraction of the polymer framework.

$$
\tau=\left(1+V_{p}\right) /\left(1-V_{p}\right)
$$

As the porosity of the membrane used in this work was $0.57-0.59$, the tortuosity calculated from Eq. (19) was $2.4-2.5$. The diffusivity of the copperoxime complex in bulk organic solvents has been reported by Hughes et al..$^{9}$. The diffusivity of the copper-oxime complex in the supported liquid mem- 


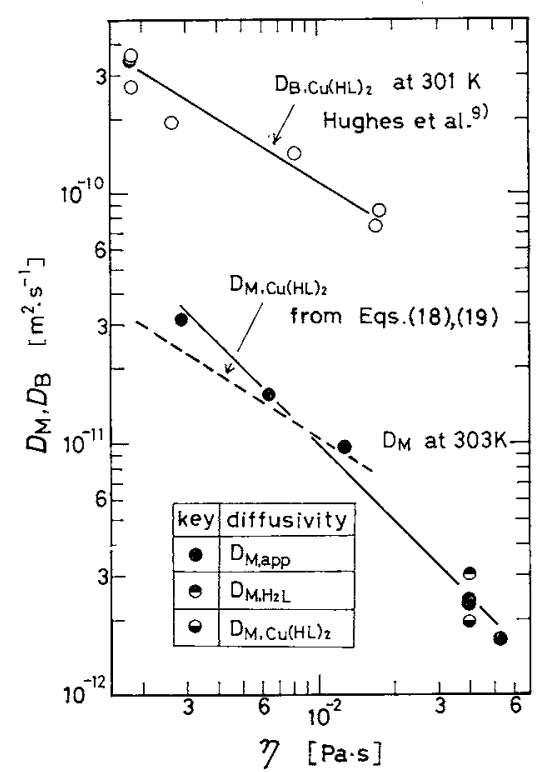

Fig. 6 Effect of viscosity of liquid membrane solution on diffusivity

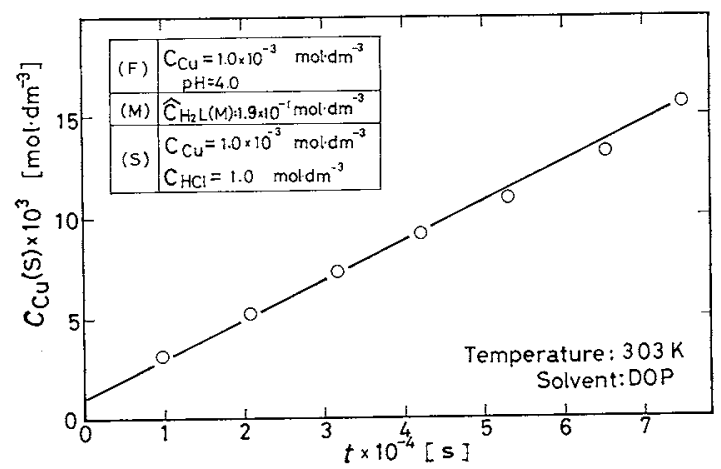

Fig. 7 Enrichment of copper

brane was calculated from Eqs. (18) and (19) by using their data shown in Fig. 6. The experimental values of $D_{M}$ are approximately in agreement with the calculated ones in the range of $\eta<2.0 \times 10^{-2} \mathrm{~Pa} \cdot \mathrm{s}$ as shown in Fig. 6.

\section{3 Permeation rate of copper}

Figure 7 shows the time-dependence of the copper concentration in the stripping solution. The copper concentration in the feed solution was maintained at $1.0 \times 10^{-3} \mathrm{~mol} \cdot \mathrm{dm}^{-3}$ by circulating the solution. The initial concentration of copper in the stripping solution was $1.0 \times 10^{-3} \mathrm{~mol} \cdot \mathrm{dm}^{-3}$. Copper transport across the membrane is coupled with the hydrogen ion transport in the opposite direction. Provided that a steep gradient of hydrogen ion concentration exists, copper transport against its concentration gradient occurs. As shown in Fig. 7, copper in the stripping solution can be concentrated much greater than the concentration in the feed solution.

The infiuence of $\mathrm{HCl}$ concentration in the stripping solution in the upper cell on the copper flux was examined in the range of $\mathrm{HCl}$ concentration of $0.1-$

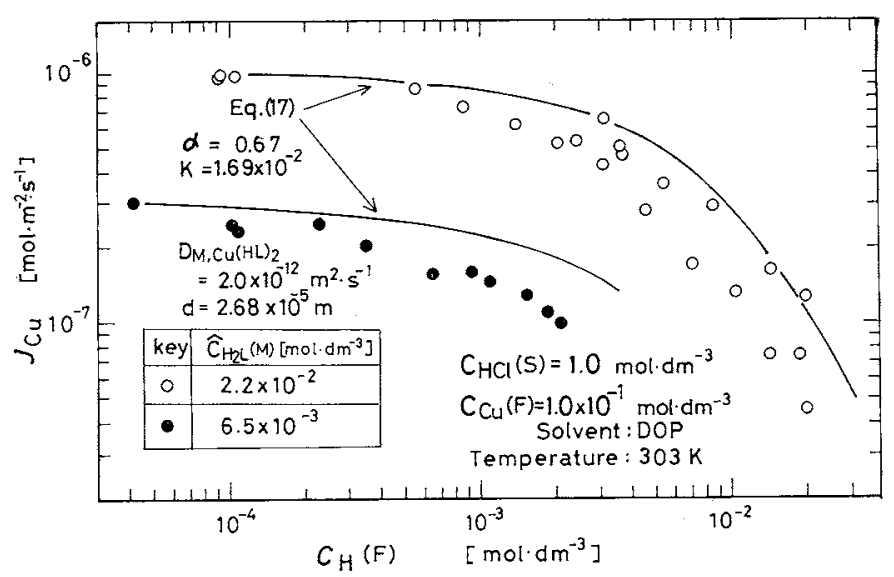

Fig. 8 Effect of pH of feed solution on copper flux

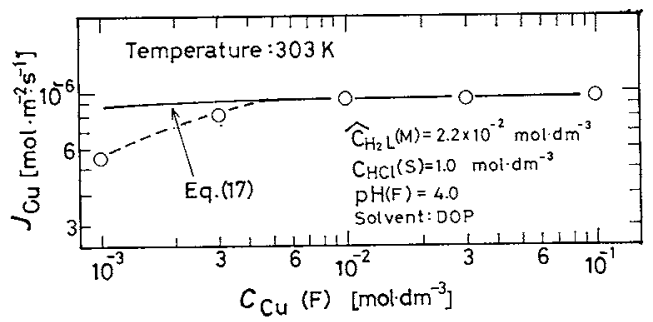

Fig. 9 Effect of copper concentration in feed solution on copper flux

$3.0 \mathrm{~mol} \cdot \mathrm{dm}^{-3}$ in order to confirm the assumption of $\left.C_{\mathrm{Cu}(\mathrm{HL})_{2}}\right|_{d}=0$. It was found that hydrogen ion concentration had little effect on copper flux under the present experimental conditions.

Figure 8 shows the effect of $\mathrm{pH}$ of the feed solution in the lower cell on the copper flux. The $\mathrm{pH}$ value of the solution in the upper cell was held constant with $1.0 \mathrm{~mol} \cdot \mathrm{dm}^{-3} \mathrm{HCl}$ solution. The flux of copper calculated from Eq. (17) is in agreement with observed values.

Figure 9 shows the effect of copper concentration, $C_{\mathrm{Cu}}(\mathrm{F})$, in a feed solution of $\mathrm{pH}=4.0$ on copper flux. In the range of $1.0 \times 10^{-2}-1.0 \times 10^{-1} \mathrm{~mol} \cdot \mathrm{dm}^{-3}$, the experimental value of the copper flux agreed with the calculated value from Eq. (17). This tendency is in good agreement with the result of Largman et al. ${ }^{131}$. However, the flux gradually deviated from Eq. (17) in the range of $C_{\mathrm{Cu}}(\mathrm{F})<1.0 \times 10^{-2} \mathrm{~mol} \cdot \mathrm{dm}^{-3}$.

Figure 10 shows the effect of oxime concentration in the liquid membrane on copper flux. The copper flux was proportional to the 1 st power of oxime concentration when $\mathrm{pH}$ of the feed solution was 4.47, and agreed with the calculated value from Eq. (17). In the lower $\mathrm{pH}$ region, the copper flux deviated from Eq. (17), but the tendency of the relationship between copper flux and oxime concentration was in agreement with the predictions from Eq. (17).

Figure 11 shows the concentration profile of the copper-oxime complex in a stack of the membranes. The concentration of the complex decreased approxi- 


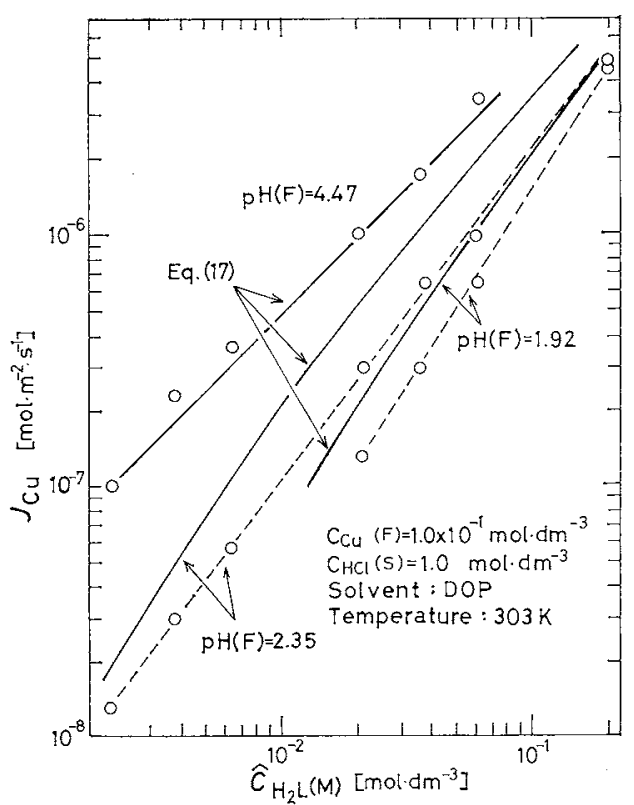

Fig. 10 Effect of carrier concentration on copper flux

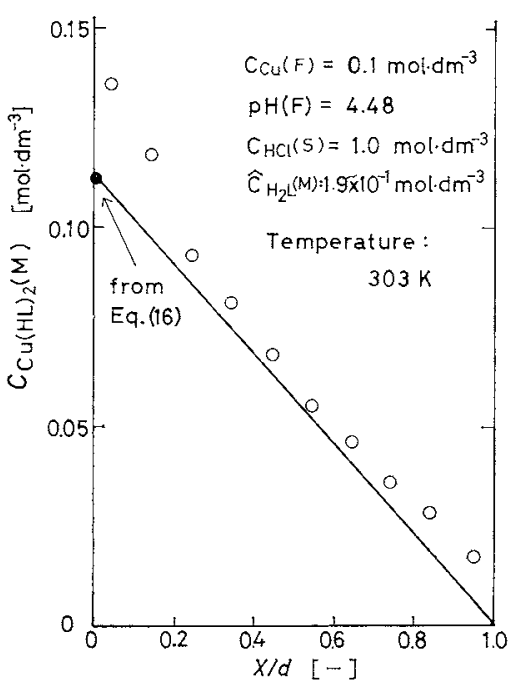

Fig. 11 Concentration profile of copper-oxime complex in liquid membrane

mately linearly with $x / d$ under a steady-state condition. This result confirms the assumptions made in Section 2.

\section{Conclusion}

1) Extraction constants of copper with a solution of LIX65N in phthalic acid diesters were obtained as shown in Table 1.

2) Diffusivities of the oxime and the copper-oxime complex and the apparent diffusivity in the supported liquid membrane were determined by the time lag method. The apparent diffusivity of copper-oxime complex in the permeation process was proportional to the -1.0 power of the viscosity of the membrane solution.
3) The copper flux was constant in the range of $\mathrm{pH}>3$ of the feed solution and decreased with decreasing $\mathrm{pH}$ in the range of $\mathrm{pH}=1.5-3$. Copper flux was proportional to oxime concentration in the supported liquid membrane when the $\mathrm{pH}$ of the feed solution was 4.47 , and agreed with the calculated value from Eq. (17). Copper concentration in the stripping solution had little effect on copper flux. The experimental results were well explained, assuming that the rate-determining step was the diffusion of the copperoxime complex in the membrane.

4) Concentration profile of the copper-oxime complex in a stack of the supported liquid membrane under a steady state was approximately linear with $x / d$ as shown in Fig. 11.

\section{Acknowledgment}

The authors are deeply grateful to Polyplastics Co., Ltd. for supplying polypropylene membranes, Duragard 2500 , used in this work.

\section{Nomenclature}

$C_{i}(\mathrm{aq})=$ concentration of chemical species $i$ in

$C_{i}(\mathrm{~F}) \quad=\quad$ concentration of chemical species $i$ in

feed solution $\left[\mathrm{mol} \cdot \mathrm{dm}^{-3}\right]$

$C_{i}(\mathrm{M}) \quad=$ concentration of chemical species $i$ per unit volume of membrane phase $\left[\mathrm{mol} \cdot \mathrm{dm}^{-3}\right]$

$C_{i}$ (org) $=$ concentration of chemical species $i$ in organic phase $\left[\mathrm{mol} \cdot \mathrm{dm}^{-3}\right]$

$C_{i}(\mathrm{~S})=$ concentration of chemical species $i$ in stripping solution $\left[\mathrm{mol} \cdot \mathrm{dm}^{-3}\right]$

$\hat{C}_{\mathrm{H}_{2} \mathrm{~L}}(\mathrm{M})=$ total (analytical) concentration of oxime in membrane phase $\quad\left[\mathrm{mol} \cdot \mathrm{dm}^{-3}\right]$

$D_{B, i} \quad=$ diffusivity of chemical species $i$ in bulk organic solution $\quad\left[\mathrm{m}^{2} \cdot \mathrm{s}^{-1}\right]$

$D_{M, i} \quad=$ diffusivity of chemical species $i$ in membrane $\left[\mathrm{m}^{2} \cdot \mathrm{s}^{-1}\right]$

$D_{s} \quad=$ binary diffusivity for solute-solvent system $\left[\mathrm{m}^{2} \cdot \mathrm{s}^{-1}\right]$

d $\quad=$ membrane thickness [m]

$E \quad=$ distribution ratio $\left(=C_{\mathrm{Cu}^{(\mathrm{HL})_{2}}}(\mathrm{org}) / C_{\mathrm{Cu}}(\mathrm{aq})\right)$

$J_{i} \quad=$ flux of chemical species $i \quad\left[\mathrm{~mol} \cdot \mathrm{m}^{-2} \cdot \mathrm{s}^{-1}\right]$

$K \quad=$ extraction constant based on unit volume of membrane $\left(=K_{\mathrm{ex}} / \varepsilon\right) \quad[-]$

$K_{\mathrm{ex}} \quad=$ extraction constant defined by Eq. (8) [-]

$\begin{aligned} Q_{t} \quad= & \text { total amount of diffusing solute across } \\ & \text { membrane unit area at time } t \quad\left[\mathrm{~mol} \cdot \mathrm{m}^{-2}\right]\end{aligned}$

$t=$ time [s]

$V_{p} \quad=$ volume fraction of polymer framework [-]

$x \quad=$ coordinate across membrane $\quad$ [m]

$\alpha \quad=$ ratio of diffusivity $\left(=D_{\mathrm{M}, \mathrm{Cu}(\mathrm{HL})_{2}} / D_{\mathrm{M}, \mathrm{H}_{2} \mathrm{~L}}\right) \quad[-]$

$\varepsilon \quad=$ porosity [-]

$\tau \quad=$ tortuosity $[-]$

$\eta \quad=$ viscosity of membrane solution $\quad[\mathrm{Pa} \cdot \mathrm{s}]$

$\langle$ Subscripts〉

$\mathrm{Cu}=\operatorname{copper}(\mathrm{II})$

$\mathrm{Cu}(\mathrm{HL})_{2}=$ copper-oxime complex

$d=$ interface between membrane and stripping 


$\begin{array}{ll} & \text { solution } \\ \mathrm{H} & =\text { hydrogen ion } \\ \mathrm{HCl} & =\text { hydrochloric acid } \\ \mathrm{H}_{2} \mathrm{~L} & =\text { active oxime in LIX65N (free oxime) } \\ 0 & =\text { interface between membrane and feed solution }\end{array}$

Literature Cited

1) Ashbrook, A. W.: Coord. Chem. Rev., 16, 285 (1975).

2) idem: J. Chromatograph, 105, 141 (1975).

3) Baker, R.W., M.E. Tuttle, D.J. Kelly and H.K. Lonsdale: J. Membrane Sci., 2, 213 (1977).

4) Choy, E. M., D. F. Evans and E. L. Cussler: J. Am. Chem. Soc., 96, 7085 (1974).

5) Crank, J.: "The Mathematics of Diffusion". p. 49, Oxford Univ. Press (1975).

6) Cussler, E. L.: $A I C h E J ., 17,1300$ (1971).

7) Duffey, M. E., D. F. Evans and E. L. Cussler: J. Membrane Sci., 3, 1 (1978).

8) Hochhauser, A. M. and E. L. Cussler: AIChE J. Symp. Ser., 71, 136 (1975).

9) Hughes, M. A., H. C. Sergeant, R. J. Whewell: J. Inorg.
Nucl. Chem., 41, 1603 (1979).

10) Kataoka, T., T. Nishiki, Y. Tamura and K. Ueyama: $J$. Chem. Eng. Japan, 13, 35 (1980).

11) Kojima, T., J. Tomita and T. Miyauchi: Kagaku Kogaku Ronbunshu, 5, 476 (1979)

12) Komasawa, I., T. Otake and A. Yamada: J. Chem. Eng. Japan, 13, 130 (1980).

13) Largman, T. and S. Sifniades: Hydrometallurgy 3, 153 (1978).

14) Lee, K. H., D. F. Evans and E. L. Cussler: $A I C h E J ., 24$, 860 (1978).

15) Mackie, J. S. and P. Meares: Proc. Roy. Soc. London, Ser. A, 232, 498 (1955).

16) Martin, T. P. and G. A. Davies: Hydrometallurgy, 2, 315 (1976/1977).

17) Völkel, W., W. Halwachs and K. Schügerl: J. Membrane Sci., 6, 19 (1980).

18) Ward III, E. J.: AIChE J., 16, 405 (1970).

19) Whewell, R. J., M. A. Hughes and C. Hansen: J. Inorg. Nucl. Chem., 38, 2071 (1976).

\title{
COMPOSITION OF SOLID CONDENSATE ON A COLD SURFACE FROM A MIXED ORGANIC VAPOR
}

\author{
Masakuni MATSUOKA and Hidekazu KOMIYA \\ Department of Chemical Engineering, \\ Tokyo University of Agriculture and Technology, Tokyo 184
}

\begin{abstract}
A method to estimate the composition of solid condensate from a binary vapor in fractional sublimation accompanied by an entrainer gas is derived, including an overall coefficient for condensation of the individual components. The coefficient was empirically correlated with gas flow rates, surface temperatures of condenser, and condenser dimensions. Good agreement between the estimated and observed compositions of the condensates was obtained for two eutectic-forming organic mixtures and one solid solution organic mixture.
\end{abstract}

\section{Introduction}

Although sublimation has been used to purify a number of substances in the laboratory and in industry its practical use has been limited to the removal and/or recovery of one or more volatile components from a solid mixture ${ }^{3)}$. In the case of one volatile component, the process is essentially condensation of a single vapor from a gas. Meanwhile, condensation of a mixed vapor composed of volatile substances is considered to form a solid mixture of which compositions are determined by the operating conditions

\footnotetext{
Received October 4, 1980. Correspondence concerning this article should be addressed to M. Matsuoka. H. Komiya is at IBM Japan, Ltd., Tokyo 106.
}

as well as the phase equilibria. Thus more knowledge of the factors affecting the rate of condensation and resulting solids physical properties is required ${ }^{4}$. However, studies of fractional sublimation ${ }^{3,6,7)}$ have been aimed mainly at the development of apparatus, and methods of estimation of product compositions have not been established.

Among the studies of fractional sublimation, Reid ${ }^{3}$, who seems to be the first author in this field, presented the idea of fractionation by utilizing the solid-vapor phase change in a continuous countercurrent multistage apparatus. He carried out several runs at a reduced pressure with a helical tube of six turns rotating on a horizontal axis, which is partially sub- 